\title{
Basic Solutions to Waste Management Issues That Will Bring Clean Culture in India
}

\author{
Bharati Koot ${ }^{1}$ \\ 1305-Gulmohar Imperial, Dhayari, Pune - 411041, India
}

\begin{abstract}
The latest population of India is around 1.37 billion and India ranks number two by population in the world. With the increasing population, the obvious thing, the waste generated per day continues to increase. India generates around 65 million tonnes of waste every year and out of which most of the part is not collected, remains untreated at landfills or open areas. This is ruining the beauty of India. And this is already impacting largely on environment, climate, soil, water bodies, national health, and tourism. That also means the waste in India is heading to largely affect the national economy and the global environment. This paper attempts to go back to the basics of human nature and habits, needs and mechanisms for shifting them for the context of waste management and anti-littering to bring clean India forward and contribute to preventing the global environmental crisis.
\end{abstract}

\section{Introduction}

This section depicts the introduction to the topic of this paper.

Littering and poor waste segregation are a few of the key factors which make waste management difficult in India and everywhere. Littering has become the most convenient habit of people unknowingly since the past decades. Waste segregation rules have been in place since the year 2006, and after that also there are revisions to waste management rules, yet we lack in implementing it. India is a country of huge population and hence sometimes it lacks the infrastructure to establish the grounds for clean surroundings. But, in recent years many initiatives have been started by the government, NGOs, and individuals. These initiatives are a very welcome step towards the clean India dream. But the question still remains, are they enough? The impacts of poor waste management and littering habits on the global environment, national reputation and economy are threats to the world and the country. So, we really need to ask another important question to ourselves, are we going to the roots of the problem? Because the problem is so crucial from a local and global point of view, we must have concrete results soon across the nation and worldwide. And, hence when it comes to addressing city waste and litter solutions, we must go to the roots.

\section{The Problems}

This section briefly describes the problem due to increased waste generation and poor waste management.

The modern lifestyle, industrialization, urbanization, and the convenience brought by the magic called plastic has increased waste generation per person or per family.
India generates around 65 million tonnes of waste every year and out of which most of the part is not collected, remains untreated at landfills or open areas. Landfills are the $3^{\text {rd }}$ largest cause of greenhouse emissions in India [1]. They cause air, food, land, and water pollution. The toxic leachate generated at landfills and landfills catching up into fire is creating a severe impact on our life and environment. The lives of other animals are at risk. We are putting our next generations in danger. Plastic waste has become a major problem to the planet as oceans are full of plastic and micro-nano plastics are already entering the food chains. The lives of people working in waste management are at risk. Approximately $80 \%$ to $90 \%$ of waste handling workers die at the age of 45 to 55 due to side effects caused by handling the waste in an unsafe manner.

On one side we need to have proper waste handling and treatment mechanisms and on the contrary, there is a need for a major shift in the mindsets of people. The lack of infrastructure is not the only problem. The unintentional casual mindset towards waste and the environment is also a problem. Hence waste management and cleanliness should become a "Peoples Movement".

\section{Recent Activities Addressing the Problem Area}

This section briefly describes various (not all) initiatives taken by the government and non-government entities in India for addressing the waste-related problems.

The government and non-government bodies have understood the need for a change from national and global perspectives.

The initiatives like "Swachh Bharat Mission" [2], "Smart Cities Mission", "AMRUT (Atal Mission for Rejuvenation and Urban Transformation)" [3] are few to

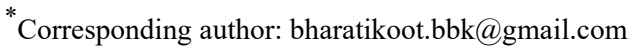


mention that government announced and is implementing across the nation.

Apart from these, many individuals, environment activists, waste warriors, NGOs, organizations are working to support government mission and national agenda about cleanliness and waste management.

These are bringing a positive change for sure in the society and country. Awareness under such programs is creating impact by spreading the word about sustainability and cleanliness. The cities like Indore, Bangalore, and Pune are ahead with the local community participation for awareness and cleanliness.

Yet, littering is a major hurdle in achieving big outcomes with such initiatives. We need the entire population to align with the national agenda to see the dream come true of clean India. The cleanliness in society creates a positive and optimistic environment around and that helps to boost creativity, wealth, happiness, and peace.

We need to put huge efforts into understanding the root causes and bringing solutions in the right direction with the right investment of money and resources.

As a citizen of India, everyone should understand how much the government needs to spend to clean up the country every day and still we are one of the unclean countries in the world.

We should encourage ourselves to take responsibility for own waste and let the government invest in other important things like education, national security, science, and technology.

We have many examples of global environmental activists, including the young generation, for example, Greta Thunberg. We have many countries that are the inspiration for bringing clean cities and clean habits like Germany, Canada, Singapore, Sweden, etc. We should learn from these inspirations.

What it takes at the heart of cleanliness is the love for our nation and our planet.

\section{Root Causes}

After describing the problem area, this section puts light on the root causes of the waste-related situation in India.

Any problem can be effectively addressed by reaching to the roots of it. A big reason behind waste management issues in India is that littering and dumping mixed garbage. The less sensitive and self-centric nature, poverty is another root cause.

The other factors are important in solving wasterelated problems like infrastructure and mechanisms, but without having addressed the root causes, the efforts in these will be in vain.

We have given the message to the world, "Vasudhaiva Kutumbakam" [4] which means "The whole world is one family". We all must revise the meaning of this message for ourselves. If everyone understands this message, we will start caring for the world as we care for our limited family and little private homes. So, when we look at these root causes, we need a major shift on an individual level spreading across the nation. And to sustain that shift for our future generations, we should connect this shift to the education systems and ruling systems. Let's see in detail the root causes behind the waste problems in India.

\subsection{Littering}

Littering is an act of disposal of any waste item on undesired locations like roads, public places, etc. This act is impacting the environment in many ways. In general, littering is a normal act, the act as easy as the way we breathe. When we inhale and exhale, we hardly pay attention to it unless something serious is there, otherwise, it goes on naturally as long as we are alive. Littering is perceived in the same way. Littering seems to be second breathing sometimes. Most of the public do not know why they litter.

\subsubsection{Unconscious Littering}

Someone walks on the road, they get some advertising pamphlet on the way, they don't even read it, and it falls unknowingly on the road without their conscious attention. This is unconscious littering. These acts happen in public places like railway stations, parks, roads, bus stops, within vehicles, and while traveling. It hardly matters to understand where the litter goes in the end as the act of littering happens unknowingly. But the thing often missed to understand is that the littered items will remain on this planet itself unless attained. And otherwise, through obvious mediums, they end up in the soil, water bodies, oceans, and in the end our food chain.

\subsubsection{Conscious Littering}

Another way of littering is conscious littering. In this case, people know littering is bad, but somehow, someone else has already done it, and they don't find any good reason not to do it. They follow that first "someone". The psychology here is to assume that littering is a free act, it's not a crime, no one is going to ask penalty, no one is watching, and in fact, the place is already unclean. So, people again unintentionally follow the tribe called the "litter tribe". This type of tribe is very dangerous as they create mass litter piled on roadside and community areas. It only starts with the first person who chooses to litter. Others blindly follow without taking efforts to look at surrounding solutions. This not only makes the surrounding ugly but also creates serious health effects for animals and humans around.

\subsubsection{Littering and Bystander Effect}

Littering is a perfect example of the Bystander effect [5]. As per the source, it is defined as, "a social psychological claim that individuals are less likely to offer help to a victim when other people are present; the greater the number of bystanders, the less likely it is that one of them will help." [5]. It is like everyone is in the hope loop waiting for one to act and help.

When we look at the bystander effect for wasterelated or littering habits, we can relate to what we see in society. The bystander observers continue staying in the hope loop that someone will act, someone, will clean up the space. It derives totally opposite behaviours in clean vs unclean place. At the place which is clean, it is less likely that people start littering. And opposite to that at the place which is unclean or becoming unclean, it is more likely that people will continue littering. And that 
is how the "litter tribe" grows. We as humans naturally tend to imitate the behaviours of others. But the point that is often missed here is that if one starts caring and acting for cleanliness, others will also start. The power of an individual can create big changes. The power of millions of individuals summed up together can create long-lasting changes. The sense of collective responsibility and collective ownership needs to be imposed in the public to deal with problematic social behaviours like littering.

And that means incorrect, misdirected social and individual behaviours are the root causes behind the littering and waste related crisis.

\subsection{Mixed Waste}

Mixed waste is very difficult to process. The major waste categories in India are degradable waste e.g. Food waste, paper waste, non-degradable waste e.g. plastic, and hazardous waste e.g. sanitary, medical waste. There are other types of waste which include metal, glass, fabric, e-waste, and industrial waste.

But, in most parts of India, the household waste collected daily turns out to be a mixed waste. The unsegregated waste is harmful to the people operating on it. The recycling and treatment of waste remain a big issue due to mixed waste. The regions where the waste collection doesn't happen, the mixed waste lands up in nature. Such mixed waste is then also littered in water bodies and drainages. They contaminate the water and surrounding air in large quantities.

So, mixed waste causes difficulties and need more resources to handle it.

\subsection{Less Sensitive and Self-centric Human Nature}

Another aspect that is widely assumed that cleaning is the duty of only a few people appointed by the government or related sectors. That means, "we pay taxes, so the government should take care of anything that is beyond my personal belonging and beyond my own doorstep" is a common unintentional attitude. This has also a psychological aspect. We want our house to be clean and neat. So, what happens in the neighbouring yard is naturally out of our scope. Also not following rules and policies is a major hurdle. There needs to be a strong awareness and strong force on following the rules and regulations. The force not necessarily has to come from respected sectors, we as common public also can ensure that every other person is following the rules. But we hardly do that. We focus on own life only.

And this means the increasing self-centric human nature is also a root cause.

\subsection{Poverty}

The poverty is another root cause. The reason is for obvious reasons, poor people buy items which they can afford and plastic is one of those as it is cheap. The products which are not durable go early into the waste. There is no blame on people who are economically backward. It is just that they don't find any option to make a living. Also, usually, they stay away from education due to poor financial situations and do not learn what's going on in the world and the environment. Many times, they are unaware of the government rules and policies about waste management. The lack of finances keeps them with a lower standard of living which means lower cleanliness and hygiene standards. The sustainable solutions which are currently available in the market are not affordable by most of the population.

So empowering economic growth and per capita income is something we need to address to solve wasterelated issues.

\section{Addressing the Root Causes}

This section points out the solutions for addressing the above-discussed root causes so that we are able to solve the problem area defined earlier.

The following are the points to elaborate on in this section.

1. Public Knowledge and Awareness

2. Adopting Sustainable Lifestyle Habits

3. Upgrading Education System

4. Building more Humane Culture

5. Sustainable Solutions - Investing in Waste

6. Decentralized Waste Management

7. Economic Growth and Increasing Per Capita Income

8. Clean Strategies, Laws, and Policies

\subsection{Public Knowledge and Awareness}

Public knowledge and awareness on a national scale is a very important step in this path. This is because the casual nature of dealing with waste has made people unaware of its effects on the environment and themselves. Such programs can be arranged by anyone the government, schools, colleges, corporates, community groups, NGOs, etc.

Knowledge and awareness programs should cover the following aspects.

1. Awareness of the current amount of waste generation and landfill sites, and their side effects.

2. Knowledge about global environmental effects due to waste issues that we have and the crisis situations that are nearing if we do not act.

3. Information about where we stand in the globe about cleanliness and waste management and what we can do to feel proud of being Indian.

4. Awareness of national vision about waste management and cleanliness

5. Awareness of global vision of environment and sustainability, for example, Sustainable Development Goals (SDG) [6] declared by the United Nations (UN).

6. Knowledge about the current policies, rules, and regulations regarding waste management and consequences if they are not followed.

7. Knowledge about waste management pyramid and how to minimize the use of landfills with the help of it.

8. Knowledge about waste segregation and waste processing at the source. 
9. Knowledge about a sustainable lifestyle for example zero waste lifestyle.

10. Awareness about the national agenda for contributing to Sustainable Development Goals (SDG) [6].

\subsection{Adopting Sustainable Lifestyle Habits}

Personal habits play a major role in dealing with wasterelated issues. They are difficult to change as they belong to an individual and become part of their lifestyles. But we can change them by practice if we determine to do so.

We do heavy plastic consumption due to the convenience that it offers. "Use and Throw" culture has grown up in recent years because of the need and comfort that comes along. The family structures have changed as situations demand the same. And all these things are causing more trash. However, we don't really need to go back to old styles, we only need to live the new lifestyle in a sustainable way.

So, when it comes to the habits in the area of waste, the following key things can be considered to create a huge environmentally positive impact.

1. Strictly prohibiting single-use plastic items.

2. Find alternatives for plastic made consumer products. We can talk to our grandparents to learn from there age how they lived with less plastic. And we can use today's creativity and technology to bring those alternatives.

3. Keeping track of our household waste will make us sensitive and help to find the motivation to reduce waste.

4. When we buy goods and products, we must think of the necessity of buying and its environmental effects after use or disposal.

5. Instead of "Use and Throw" products, we should go for sustainable products that last longer and reused many times. Those include items made from metal, glass, cloth, stone, paper, wood, etc.

6. We should donate excess items that we do not use but somebody else can use it.

7. Zero waste is a new lifestyle which makes living with zero-waste generation. By following environment-friendly products, the zero-waste lifestyle is achievable.

8. Littering must never be a choice. As we keep our home clean, we shall strive to keep our surroundings clean.

9. And above all educate the next generations regarding all these aspects.

\subsection{Upgrading Education System}

The education system needs significant changes. The knowledge and awareness that we talked about in section 5.1 should be part of the education syllabus. That will motivate kids to become more responsible citizens when they grow up. We can shape kids and teach good habits at an early age when their brain is ready to accept those things promptly. And it is very essential that their brain captures the right habits in the right age for the reason that they develop their personality for the rest of their life.

When we want to develop changes in the education system following things are the highlights.

1. The Education system should have practical exposure along with mere theoretical concepts.

2. The syllabus must include the environment, climate change, waste management as a compulsory topic with theory and practical.

3. Various educational sessions must be arranged for students for current scenarios of waste and environmental effects.

4. Various events must be arranged to encourage students to express creativity and innovation keeping environment and waste management as a central topic.

5. Good habits can be cultivated very effectively in schools by teachers. So, the teachers must lead by example and teach by example.

6. Education shall include effects not only on the environment but on the lives of waste pickers and their families.

7. Like industry visits, similar visits for students should be arranged which include visits to recycling units, landfill sites for site observation and study, visits to waste pickers families to learn their situation and issues.

8. As like inter-school sports competition, there should be inter-school cleanliness events to bring the motivation-based cleanliness culture.

\subsection{Building More Humane Culture}

Dealing with waste is a "Humane" thing. The selfcentric nature of people these days is one of the reasons behind waste-related issues. The life of today is fast and technology-driven. People have own comforts and problems to deal with. And due to that, there are less chances of willingness to deal with social issues. The self-centric habits lead to acting less responsibly in society. The littering, spitting, the garbage piled roads are outcomes of this nature.

We care little about the families who work for cleanliness and waste processing. That is not because we do not want to care but because we are not exposed to their situations and worries. It is totally unfair that the waste produced by a larger population is handled by very little population and for less reward in return. This quote says that all - "We can't have landfills forever and we can't ask others to accept our trash. - Jaime Lerner". We must think more responsibly and humanely. And we can do the following for that.

1. Taking responsibility for own waste.

2. Strictly avoid littering under any circumstances.

3. Keeping public places and washrooms clean.

4. Being more sympathetic towards waste pickers and their families.

5. Providing safety kits like gloves, masks, shoes, sanitizers to the people who handle the waste.

6. Demanding a safe and healthy infrastructure for waste pickers. 
7. Respecting the people who clean our surroundings, public places, and handle our daily waste.

8. Following the rules and regulations around waste management.

9. Educating the people who deal with the waste about new rules and regulations so that they can expect it from people.

10. Supporting for the education of children from waste pickers families.

11. Incentivizing those people for the great contribution they do for society and the environment.

12. Arranging recreational and rewarding events for the people and the families who handle the waste.

\subsection{Sustainable Solutions - Investing in Waste}

Along with awareness, education, and public knowledge, another aspect is bringing sustainable solutions so that people can use them. Investing in waste is a new need for today. That investment could be in education as we talked about it in section 5.3 or it could be in the industry and market. People will be more willing to contribute if they find alternatives in the market. Industrialists will be more willing to change if they understand the need and that they will not lose anything but just shift the production to sustainable goods. This will not have any effect on labour or existing business outcomes if they plan properly.

While we promote a sustainable lifestyle, we need to bring up sustainable alternatives in the market and that to at affordable prices. We can make surveys of current sources of waste and contents of waste to find out what solutions need to be brought up first on a large scale. That information can be also made available to the public for awareness. Plastic is definitely on the radar that must be minimized as far as possible. That means the study of municipal solid waste and current consumer options can help us invest in the right solutions.

This will generate new income streams and also replace existing non-sustainable income streams to sustainable income streams.

The government subsidization and incentivization must be available to businesses and NGOs who work for bringing sustainable solutions. This will encourage people to use modern technology in a sustainable way to bring solutions. This way the overall national creativity and innovation will increase.

In all, we can think of following in this regard.

1. Promoting sustainable goods and businesses, recycling projects, waste to energy projects.

2. Subsidize or incentivize businesses and NGOs working in sustainable solutions and environmental issues.

3. Investing in education as mentioned in section 5.3

4. Investing in public awareness and training.

5. Make sustainable goods available at affordable prices for consumers.

6. The key areas like supermarkets, malls, vegetable and fruit shops, milk vendors, restaurants, medicals should restrict using plastic bags and plastic items as far as possible and invest in sustainable alternatives.

7. Investing in recycling units.

8. Investing in segregation units.

9. Composting projects for all the religious places for the used flowers and leaves.

10. We should invest in infrastructure for proper and hassle-free waste management. This includes segregation bins at households, commercial places, public places, advancedautomated waste processing machines, modern waste transport vehicles preferably e-vehicles.

11. We should give the market for by-products of waste management, for example, compost or energy generated after waste processing.

\subsection{Decentralized Waste Management}

At present, the waste flows from households or industries to specific landfill sites that are away from the city area. This adds the costs of transport, middle agents like waste collectors, and adds up to city traffic and environmental pollution. We need to break down this system to a decentralized one.

The decentralized waste management implies the waste is processed within the same block or zone where it is collected. This avoids unnecessary transportation to longer distances. The solid waste management should be done in such a way that, wet waste has a composting facility in each block and other waste recycling and processing units are present in each block. Each block will have authority in charge of waste management and cleanliness. The local issues and concerns can be solved in a faster way with this system.

This way we are going to invest initially some extra money but the benefits are long terms. This will also create a competitive environment where each block will strive to be cleaner and zero waste. Part of this also is to encourage people to participate in waste processing at the source itself like at households, at townships, at residential zones, etc.

\subsection{Economic Growth and Increasing Per Capita Income}

Poverty or uneven distribution of wealth is another root cause behind waste-related issues. Poverty leads to a lack of education, knowledge, and unsustainable product usage on a large scale.

The equation that the rich become richer and poorer remains poor must be changed. For that, not only the government but the people from society also should come forward to uplift each other economically. Creating an environment where everyone has a basic living standard, employment to fulfill that living standard, education, and health facilities shall be created. Here, education is the key.

We should leave a self-centric nature and think beyond that. Few rich people, NGOs, the government are already doing a lot for this, however, that is not enough. If we all grow together then only, we will bring clean and wealthy India together. 
The villages, slums, low-income farmers, lowincome workers, and similar people and their children should be our focus to work on eliminating poverty. Various schemes announced by the government must be easily accessible to these people without any intervention that they can take benefit of those. The employment rate should be increased. The local and global investments in business and market should be promoted and supported. In our country the majority of the occupation is farming, we must introduce advanced farming methodologies to increase the income of farmers.

We must not let poverty being used as a tool for vote bank and leading to corruption. And that is why knowledgeable people and those who can spare their money and time for uplifting the society must come together to help to solve the problem of poverty along with the government.

\subsection{Clean Strategies, Laws, and Policies}

Policymakers from administration and government will play a key role in establishing the right policies and ensuring the implementation of those policies. They have broader access to the public and have a larger perspective for nation-building. On one side they can uplift key people and sectors for national building activities and on the other side, they can make policies that will lead to sustainable national development.

The policies, the rules, and the national agenda should be made accessible to the public. And provisions for not obeying the rules should be strictly imposed at the beginning of the implementation so that people act responsibly.

The following are key areas where strategic planning and policy rollout can be implemented.

1. A complete ban on single-use plastic and strict implementation of it.

2. A complete ban on plastic water bottles and establishing an alternative for purified water availability in public and required places.

3. Subsidization for businesses working for the environment.

4. Tax exemption for cleantech companies.

5. Green tax (tax dedicated for environmental impact reduction activities) provision from existing tax deductions or via new policy.

6. Continuous monitoring systems for chronic areas where people litter on a large scale so as to warn and collect fine otherwise until they stop littering.

7. Continuous monitoring systems at major water bodies and over bridges where garbage bags are typically thrown.

8. Installation of durable dustbins on large scale on roads, public places, public transport systems in an accessible manner.

9. Return and refund policies for promoting recycling of materials for example glass bottles.

10. Supporting zero waste and zero landfill projects at various blocks.

11. Strict laws and regulations for the industry byproducts which are considered as waste.
12. Laws for corporates and businesses to handle their waste.

13. Laws for waste producers to take charge of waste processing and cost involved. This will indirectly promote the reduction of waste generation.

14. Decentralization of waste collection and processing.

15. Introducing legal committee for environmental protection and actions.

16. Penalty system for breaking the environmental and waste related laws.

\section{Conclusion}

We have more population who generates waste than who cleans up and processes it. We have more population who can follow the laws and regulations than who can generate the laws and regulations. That simply means the major actors in the process of waste management are, "we, the people". If we start understanding our own waste and taking responsibility for it, we can free the government to act and invest in more important things. It's our country, it's our planet and we owe something for it. And keeping it clean for all the creatures and future generations is our sole responsibility. We don't need rocket science for acting responsibly and following laws regarding the environment and waste management. We need the mindset to act on the root causes as described in this paper and become more humane. We need to talk not just about reducing taxes but also reducing trash. We need a national mindset for bringing a clean culture, and we can achieve that if we align the entire population to that national agenda of sustainability and cleanliness.

\section{References}

1. https://www.epw.in/engage/article/institutionalframework-implementing-solid-waste-managementindia-macro-analysis

2. https://www.pmindia.gov.in/en/major_initiatives/sw achh-bharat-abhiyan/

3. http://amrut.gov.in/content/

4. https://en.wikipedia.org/wiki/Vasudhaiva_Kutumba kam

5. $\underline{\text { https://en.wikipedia.org/wiki/Bystander_effect }}$

6. https://sustainabledevelopment.un.org/?menu=1300 